Review

\title{
The antithrombotic therapy of atrial fibrillation in patients with coronary heart disease
}

\author{
Olga L. Bockeria, Tatyana G. Le
}

Bakulev Center for Cardiovascular Surgery, Moscow, Russia

Received 20 August 2018, Revised 2 October 2018, Accepted 8 October 2018

(C) 2018, Bockeria O.L., Le T.G.

(C) 2018, Russian Open Medical Journal

Abstract: Coronary heart disease (CHD) is the most common cardiovascular disease, while atrial fibrillation (AF) is the most common heart rhythm disorder. These diseases have common risk factors such as hypertension, diabetes, sleep apnea, obesity and smoking. The frequency of $\mathrm{CHD}$ in patients with $\mathrm{AF}$ ranges from 17.0 to $46.5 \%$, while the prevalence of $\mathrm{AF}$ among patients with $\mathrm{CHD}$ is low and is estimated at only $0.2-5.0 \%$. AF is a well-known factor of unfavorable short-term and long-term prognosis in patients with acute myocardial infarction; it is associated with a significant increase in overall mortality. It is assumed that in $5-15 \%$ of cases of AF, coronary artery stenting and, accordingly, triple therapy with Aspirin, Clopidogrel or Ticagrelor and oral anticoagulant will ever be required. This requires very careful consideration of balanced antithrombotic therapy, taking into account the high risk of bleeding, the risk of stroke and stent thrombosis followed by acute coronary syndrome. Co-administration of oral anticoagulants with antiplatelet drugs, and in particular triple therapy, significantly increases the absolute risk of serious bleeding. In addition, severe bleeding is associated with a fivefold increase in the risk of adverse outcome after acute coronary syndrome. The presence of atrial fibrillation with coronary heart disease worsens the prognosis even in patients undergoing careful treatment.

Keywords: coronary artery disease, atrial fibrillation, prevention, antithrombotic therapy.

Cite as Bockeria OL, Le TG. The antithrombotic therapy of atrial fibrillation in patients with coronary heart disease. Russian Open Medical Journal 2018; 7 : e0412.

Correspondence to Tatyana G. Le. Address: 135, Rublevskoe shosse, Moscow, 121552, Russia. E-mail: tanya_co@mail.ru.

\section{Introduction}

Coronary heart disease (CHD) is the most widely spread cardiovascular disease [1], while atrial fibrillation (AF) is the most common heart rhythm disorder [2]. The frequency of angina pectoris in women increases from $5-7 \%$ at the age of $45-64$ years to $10-12 \%$ at the age of $65-84$ years. In turn, angina pectoris in male aged $45-64$ years is observed in $4-7 \%$ and aged $65-84$ years in $12-14 \%$ [3]. In 2013, CHD was the leading cause of death worldwide. The mortality from CHD increased from 5.74 million (12\%) in 1990 to 8.14 million (16.8\%) in 2013 [4].

The prevalence of atrial fibrillation is generally $2 \%$ and increases with age: $0.14 \%$ in people younger than 50 years, $4 \%$ aged from 60 to 70 years, $14 \%$ in people older than 80 years $[2,5]$. CHD and AF have common risk factors such as hypertension, diabetes, sleep apnea, obesity and smoking. Moreover, inflammation plays a great role in the development of both diseases [6].

The frequency of $\mathrm{CHD}$ in patients with $\mathrm{AF}$ ranges from $17 \%$ to 46.5\% [7]. In large studies such as ROCKET-AF [8] and RELY [9], CHD was detected in $17 \%$ of patients with AF. In the study which had been carried out by Van Gelder et al., the prevalence of coronary heart disease was $18 \%$ in patients with a constant form of atrial fibrillation [10]. In the study performed by Kralev et al., $13 \%$ of patients with AF subjected to coronary angiography were diagnosed with hemodynamically significant coronary artery stenosis, and the frequency of a constant form of arrhythmia was almost identical in both groups - with and without coronary artery disease ( $30 \%$ and $27 \%$, respectively) [11]. In turn, the frequency of concomitant AF among patients with $\mathrm{CHD}$ is only $0.2-5.0 \%$ [12].

Atrial fibrillation and myocardial infarction as concomitant events

The acute myocardial infarction (AMI) is an established risk factor for AF, which occurs in $6-21 \%$ of patients in this category [13]. One patient from ten with AMI has the AF in history. Moreover, one from four patients after the AMI has AF. The study of 2,460 patients after myocardial infarction showed that the damage of the atrial branches is a risk factor for $A F$, regardless of age, sex, left ventricular ejection fraction, left atrial size, time of reperfusion or coronary blood flow on the TIMI scale after intervention [14].

$\mathrm{AF}$ is a factor of unfavorable short-term and long-term prognosis in patients with AMI. It also contributes to a significant increase in overall mortality. In patients with $\mathrm{AMI}$ and concomitant $\mathrm{AF}$ in history, mortality rates are higher than in patients without arrhythmia. The half of the first reported cases of supraventricular arrhythmias had developed within one month after acute coronary syndrome (ACS). The risk of mortality associated with AF varies and depends on terms, for example, the risk of death in the case of arrhythmia occurring within $\mathbf{3 0}$ days after AMI, twice as high as in patients without AF. In a large study involving more than 6,000 
patients with $\mathrm{AMI}$, it was noted that the first developed $\mathrm{AF}$ is a frequent and lethal complication of myocardial infarction. It is also noted that this arrhythmia is associated with a higher risk of death in the hospital and repeated hospitalizations within 30 days. Moreover, during hospitalization in patients with $\mathrm{AMI}$ and $\mathrm{AF}$ the risk of acute cerebrovascular accident increases twice [15]. These results are relevant to the GRACE study, which noted that patients with ACS and newly developed AF have a 3 times increased risk of death during hospitalization compared to those without arrhythmia [16]. In addition, these patients were almost twice as likely to have complications in the form of heart failure, and more than 3 times more often - in the form of cardiogenic shock [15]. In a large single-center study, while comparing the results of different types of $\mathrm{AF}$, among 2,980 patients with $\mathrm{AMI}$, only with a constant and newly developed form of AF, a significantly higher short-term and long-term mortality was noted, compared with patients without arrhythmia. The patients with documented paroxysmal AF had the lowest 30-day mortality (7.3\%) among subgroups with arrhythmia, similar to the group without AF (5.2\%). The 10-year mortality rate was high and did not differ significantly among subgroups [17].

In some cases, patients with AF developed thromboembolic AMI [18]. This arrhythmia is associated with signs of systemic inflammation, which can contribute to the prothrombotic state and, finally, to AMI [19]. The systemic inflammation may depend on arrhythmia as well, as on the presence of concomitant classical atherosclerosis risk factors, which are usually also associated with AF. In addition, there is another mechanism for the development of AMI in AF. For example, episodes of such arrhythmia with a high frequency of ventricular contractions can lead to the second type of AMI, which is characterized by an imbalance between the need of oxygen and the blood supply to the myocardium and is usually not manifested by the elevation of the ST segment [20]. In a large randomized ROCKET-AF study, AMI developed in 101 patients in the Rivaroxaban group and 126 patients in the Warfarin group (0.9\% and $1.1 \%$ per year, respectively) [8]. The RELY study reported a lower incidence of myocardial infarction: $0.53 \%$ per year while taking Warfarin, $0.72 \%$ per year while taking Dabigatran at $110 \mathrm{mg}$ (twice a day) and $0.74 \%$ per year while taking Dabigatran at $150 \mathrm{mg}$ (twice a day) [9].

\section{Atrial fibrillation after coronary artery bypass grafting}

The cardiac arrhythmias are not uncommon after heart surgery and occur in approximately $20-40 \%$ of patients after coronary artery bypass grafting (CABG) [21]. The postoperative AF usually develops in 2-4 days after surgery. This arrhythmia can be life-threatening, especially in the elderly and patients with left ventricular dysfunction. The postoperative $\mathrm{AF}$ is also associated with an increased risk of thromboembolic events, strokes and longer hospital stay. The study showed that the average duration of hospitalization after surgery in patients with AF was $15.3 \pm 28.6$ days compared to $9.3 \pm 19.6$ days in patients without arrhythmia [22].

\section{Angiographic results in patients with atrial fibrillation}

The patients with AF may experience chest pain, which is sometimes accompanied by transient changes in the ST segment of the ischemic character with slightly elevated cardiac markers, thus simulating coronary artery disease. The patients in this category often have a high frequency of ventricular contractions, which leads to the appearance of ST-segment depression that occurs in the background of the subendocardial ischemia. The study demonstrated that depression of ST segment was observed in $38 \%$ of patients with tachy-systolic type of the AF, and half of them according to the results of angiography were diagnosed coronary artery disease [23]. Only $4 \%$ of patients with tachysystolic type of AF without changes of ST segment on electrocardiogram (ECG) were positive noninvasive stress tests and coronary artery disease according to the results of coronary angiography [24].

ST segment depression often occurs during tachycardia even in the absence of coronary artery disease and is not specific to ischemia, especially if depression is $<2 \mathrm{~mm}$ [25]. In one study, the author found the release of troponin in $15 \%$ of patients with $\mathrm{AF}$ and symptoms of myocardial ischemia, with normal angiography data [26]. In a retrospective analysis of the database of patients who underwent coronary angiography, the presence of AF at the time of the procedure or in history was a factor associated with initial coronary heart disease [27]. Thus, patients with isolated AF and the absence of risk factors for coronary heart disease should be searched for the causes of arrhythmia. On the other hand, one study showed that patients of this group who underwent percutaneous coronary interventions $(\mathrm{PCl})$ had more frequent atherosclerotic changes in the right coronary artery compared to patients without AF [11]. The authors of this work emphasized that the presence of significant stenosis in the proximal segment of the right coronary artery and the left circumflex artery before the branches of the atria, increases the probability of supraventricular arrhythmias. A retrospective analysis of 3,220 patients who underwent selective coronary angiography showed that only $43 \%$ of patients with coronary artery disease and $\mathrm{AF}$ had atherosclerotic changes in the right coronary or left circumflex arteries. In addition, only $2 / 3$ of patients with stenoses in the coronary arteries were localized before the atria branches [28]. The single-center retrospective analysis showed that CHD in patients with AF proceeds with a higher degree of severity. In addition, patients with arrhythmia and AMI had a significantly higher number of affected coronary arteries [29].

Antithrombotic therapy after acute coronary syndrome and percutaneous coronary intervention

It is supposed that $5-15 \%$ of patients with $\mathrm{AF}$ will require coronary artery revascularization and, accordingly, triple therapy with Aspirin, Clopidogrel or Ticagrelor and oral anticoagulant. This necessitates careful consideration of balanced antithrombotic therapy, taking into account the risks of bleeding, stroke or stent thrombosis followed by acute coronary syndrome [2].

The co-administration of oral anticoagulant with antiplatelet drugs, in particular, triple therapy, increases the absolute risk of serious bleeding [30]. Several retrospective and prospective analyses compared triple therapy (dual antiplatelet therapy with oral anticoagulants) with dual therapy (dual antiplatelet therapy or oral anticoagulants with a single antiplatelet drug). The results of these studies show an increased risk of bleeding in triple therapy, an average of $50 \%$ higher compared to double therapy [31]. However, several large registries reported that the risk of serious bleeding in triple therapy is 3-4 times higher than in the case of oral anticoagulant monotherapy or using the one antiplatelet drug. It was also shown that profuse bleeding was associated with a fivefold increased risk of mortality after acute coronary syndrome [32-34]. 
Patients with AF after ACS

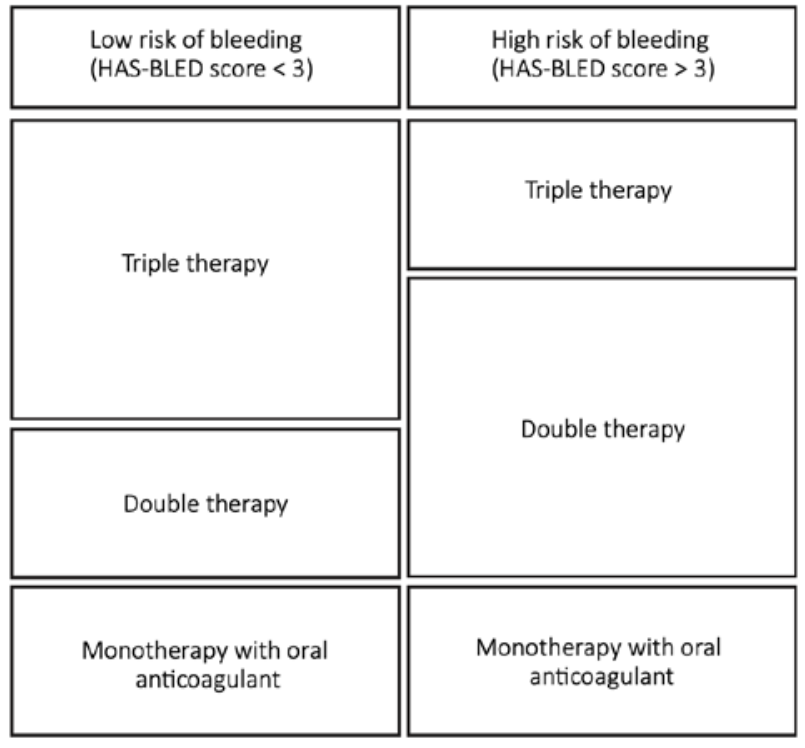

Patients with $\mathrm{AF}$ after planned $\mathrm{PCl}$

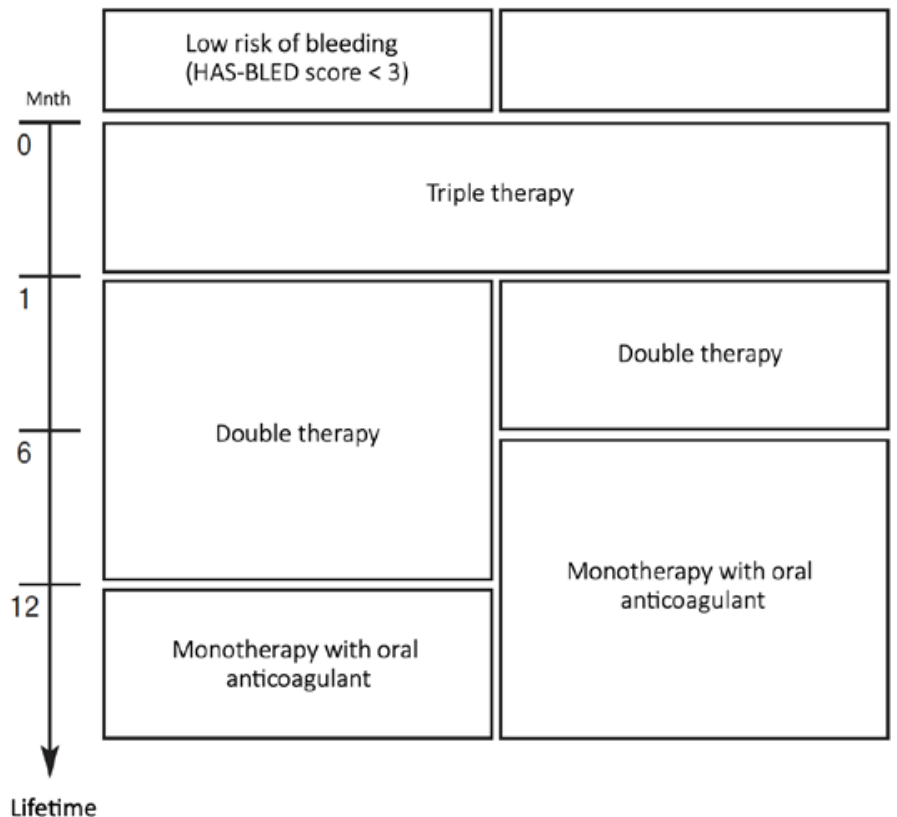

Figure 1. The treatment of atrial fibrillation depending on clinical conditions [2].

The PIONEER AF-PCl study involved patients with AF of nonvalvular genesis after $\mathrm{PCl}$ with coronary artery stenting. The administration of either a low dose of Rivaroxaban (15 mg once a day) with P2Y12 inhibitor for 12 months or a very low dose of Rivaroxaban ( $2.5 \mathrm{mg}$ twice a day) with dual antiplatelet therapy for 1, 6 or 12 months was associated with a lower incidence of clinically significant bleeding than standard Vitamin $\mathrm{K}$ antagonist therapy with dual antiplatelet therapy for 1, 6 or 12 months [35]. At the same time, all three groups had similar efficiency.

The patients with AF who have undergone coronary artery stenting were prescribed either Rivaroxaban $15 \mathrm{mg}$ daily with P2Y12 inhibitor or Rivaroxaban $2.5 \mathrm{mg}$ twice daily. The double antiplatelet therapy is associated with a reduced risk of mortality or re-hospitalization compared to the standard triple treatment regimen [36].

In the WOEST study there have been 573 patients who received oral anticoagulants (mainly because of the AF) and needed for $\mathrm{PCl}$ patients randomized to the standard group triple therapy (oral anticoagulants, Aspirin and Clopidogrel) and dual therapy (Clopidogrel and oral anticoagulants). This work has shown that dual therapy significantly reduced the risk of bleeding, and was associated with a lower risk of death or thrombosis. During one year of treatment, episodes of bleeding have been observed in $19.4 \%$ of patients receiving double therapy, against $44.4 \%$ - with triple scheme [37].

The ISAR-TRIPLE study, in which patients have been randomized in groups of 6-week or 6-month Clopidogrel therapy in addition to aspirin and oral anticoagulants after drug-coated stent implantation, revealed no significant differences between the groups in mortality rates, AMI frequency, stroke, thrombolysis in myocardial infarction or major bleeding (primary end point) [38]. In addition, there have been no differences in the combined secondary end point (cardiac death, AMI or ischemic stroke). These findings suggest that physicians should carefully balance the risk of ischemic events against the risk of serious bleeding while choosing a short-term or long-term triple therapy.

In the Re-dual-PCl study, the use of Dabigatran and P2Y12 inhibitors was studied in 2,725 patients with non-valvular atrial fibrillation who underwent planned $\mathrm{PCl}$. There was an unreliable increase in the level of individual thromboembolic endpoints in the group of double therapy with Dabigatran at a dose of $110 \mathrm{mg}$ ( 2 times a day), but according to the authors, these results should be evaluated with caution, due to insufficient evidence. Nevertheless, a significant reduction in the frequency of bleeding was demonstrated with the use of dual therapy.

The other studies on various aspects of oral anticoagulants and antithrombotic therapy are still ongoing.

The patients with AF and risk of stroke, as well as mechanical valves and recent or recurrent deep vein thrombosis or pulmonary embolism, should take oral anticoagulants during and after stenting. A short period of triple therapy (oral anticoagulants, Aspirin, Clopidogrel) is recommended, and then should be followed by a period of double therapy (oral anticoagulants with one antiplatelet drug) (Figure 1).

After planned stenting of coronary arteries, patients with AF and stable angina at risk of stroke, combined triple therapy with Aspirin, Clopidogrel and oral anticoagulant should be administered within 1 month to prevent coronary and cerebral ischemic events.

After acute coronary syndrome and stent implantation in patients with $\mathrm{AF}$ and stroke risk, combined triple therapy with Aspirin, Clopidogrel and oral anticoagulant should be administered within 1-6 months to prevent coronary and cerebral ischemic events [2]. 
After acute coronary syndrome without stent implantation, patients with $\mathrm{AF}$ and risk of stroke, dual therapy with oral anticoagulant and Aspirin or Clopidogrel should be prescribed for up to 12 months to prevent coronary and cerebral ischemic events.

The combined antithrombotic therapy, especially triple therapy, should be prescribed for a limited period of time, warning the perceived risk of recurrent coronary events and serious bleeding. The double therapy with any oral anticoagulant and Clopidogrel ( $75 \mathrm{mg}$ per day) can be considered as an alternative to triple therapy for individual patients [2].

While using new oral anticoagulants, it is recommended to prescribe the lowest effective dose for the prevention of stroke in AF [2]. The recommended combination of oral anticoagulants, antithrombotic therapy and duration of such combined therapy for patients with $\mathrm{AF}$ after $\mathrm{PCl}$ is shown in Figure 1.

In patients after acute coronary syndrome with high (uncorrectable) risk of bleeding, the duration of triple therapy can be reduced from 6 to 1 month or, in some cases, immediately replaced by double therapy (with Aspirin or Clopidogrel). The more longer-term triple therapy (up to 12 months) may be considered in individual patients who have been implanted with a firstgeneration drug-coated stent, as well as in the case of very high anti-thrombotic risk (e.g. $\geq 118$ on the GRACE scale) in combination with a low risk of bleeding on the HAS-BLED scale [39].

All patients with coronary artery disease and AF should switch to oral anticoagulants monotherapy in 1 year, except for those patients who have a very high risk of coronary events and a sufficiently low risk of bleeding [40].

\section{Conclusion}

In patients with $\mathrm{AF}$, the general prevalence of $\mathrm{CHD}$ is relatively high. The number of patients with AF who underwent PCI or CABG is also high, especially among those over 70 years. An increase in the number of risk factors for cardiovascular disease necessitates a thorough examination of patients with $\mathrm{AF}$, either to exclude or to establish a diagnosis of coronary artery disease. This may contribute to a timely and safe therapeutic strategy, including oral administration of oral anticoagulants in combination with antiplatelet drugs.

\section{Conflict of interest}

The article is written in the framework of the project of the Ministry of Education and Science of the Russian Federation within a program No. RFMEFI60717X0192.

\section{References}

1. Bockeria LA, Yarbekov RR, Sigayev IYu, Chigogidze NA, Merzlyakov VYu, Keren MA. The long-term results of coronary artery bypass grafting vs. pci with drug eluting stent in patients with diabetes and multivessel coronary artery disease. Bulletin of Bakoulev CCVS for Cardiovascular Surgery 2014; 15(5): 37-45. Russian. https://elibrary.ru/item.asp?id=23638846.

2. Kirchhof $P$, Benussi S, Kotecha D, Ahlsson A, Atar D, Casadei B, et al. ESC Guidelines for the management of atrial fibrillation developed in collaboration with EACTS. Europace 2016; 18 (11): 1609-1678. https://dx.doi.org/10.1093/eurheartj/ehw210.

3. National Institutes of Health NH, Lung, and Blood Institute. Morbidity \& Mortality: 2012 Chart Book on Cardiovascular, Lung, and Blood Diseases. Bethesda, MD: National Heart, Lung, and Blood Institute, 2012
4. GBD 2013 Mortality and Causes of Death Collaborators. Global, regional, and national age-sex specific all-cause and cause-specific mortality for 240 causes of death, 1990-2013: a systematic analysis for the Global Burden of Disease Study 2013. Lancet 2015; 385(9963): 117-171. https://dx.doi.org/10.1016/S0140-6736(14)61682-2.

5. Bockeria LA, Shengelia LD. Treatment of atrial fibrillation. Part II. Current realities and future prospects. Annaly Aritmologii 2014; 11(2): 76-86. https://dx.doi.org/10.15275/annaritmol.2014.2.2.

6. Bockeria OL, Akhobekov AA, Shvarts VA. Kudzoeva ZF. The statin therapy effect in prevention of atrial fibrillation in the early postoperative period after coronary artery bypass surgery. Annals of Russian Academy of Medical Science 2015; 70(3): 275-276. https://dx.doi.org/10.15690/vramn.v70i3.1322.

7. Hohnloser SH, Crijns HJ, van Eickels M, Gaudin C, Page RL, TorpPedersen $\mathrm{C}$, et al. Effect of dronedarone on cardiovascular events in atrial fibrillation. $N$ Engl J Med 2009; 12(7): 668-678. https://dx.doi.org/10.1056/NEJMoa0803778.

8. Patel MR, Mahaffey KW, Garg J, Pan G, Singer DE, Hacke W, et al. ROCKET AF investigators. Rivaroxaban vs. warfarin in non-valvular atrial fibrillation. $N$ Engl J Med 2011; 365(10): 883-891. https://dx.doi.org/10.1056/NEJMoa1009638.

9. Connolly SJ, Ezekowitz MD, Yusuf S, Eikelboom J, Oldgren J, Parekh A, et al. RELY Steering Committee and Investigators. Dabigatran versus warfarin in patients with atrial fibrillation. N Engl J Med 2009; 17(12): 1139-1151. https://dx.doi.org/10.1056/NEJMoa0905561.

10. Van Gelder IC, Groenveld HF, Crijns HJ, Tuininga YS, Tijssen JG, Alings $A M$, et al. Race II Investigators. Lenient versus strict rate control in patients with atrial fibrillation. N Engl J Med 2010; 362(15): 14391441. https://dx.doi.org/10.1056/NEJMoa1001337.

11. Kralev S, Schneider K, Lang S, Süselbeck T, Borggrefe M. Incidence and severity of coronary artery disease in patients with atrial fibrillation undergoing firsttime coronary angiography. PLoS One 2011; 6(9): e24964. https://dx.doi.org/10.1371/journal.pone.0024964.

12. Otterstad JE, Kirwan BA, Lubsen J, De Brouwer S, Fox KA, Corell P, et al. Action Investigators. Incidence and outcome of atrial fibrillation in stable symptomatic coronary disease. Scand Cardiovasc J 2006; 40(3): 152-159. https://dx.doi.org/10.1080/14017430600746268.

13. Schmitt J, Duray G, Gersh BJ, Hohnloser SH. Atrial fibrillation in acute myocardial infarction: a systematic review of the incidence, clinical features and prognostic implications. Eur Heart J 2009; 30(9): 10381145. https://dx.doi.org/10.1093/eurheartj/ehn579.

14. Jabre P, Jouven X, Adnet F, Thabut G, Bielinski SJ, Weston SA, et al. Atrial fibrillation and death after myocardial infarction: a community study. Circulation 2011; 17(19): 2094-2100. https://dx.doi.org/10.1161/CIRCULATIONAHA.110.990192.

15. Kundu A, O'Day K, Shaikh AY, Lessard DM, Saczynski JS, Yarzebski J, et al. Relation of atrial fibrillation in acute myocardial infarction to in-hospital complications and early hospital readmission. Am J Cardiol 2016; 15(8): 1213-1218. https://dx.doi.org/10.1016/j.amjcard.2016.01.012.

16. Mehta RH, Dabbous $\mathrm{OH}$, Granger $\mathrm{CB}$, Kuznetsova $\mathrm{P}$, Kline-Rogers $\mathrm{EM}$, Anderson FA, et al. Comparison of outcomes of patients with acute coronary syndromes with and without atrial fibrillation. Am J Cardiol 2003; 1(9): 1031-1036. https://dx.doi.org/10.1016/j.amjcard.2003.06.001.

17. Poçi D, Hartford M, Karlsson T, Edvardsson N, Caidahl K. Effect of new versus known versus no atrial fibrillation on 30-day and 10-year mortality in patients with acute coronary syndrome. Am J Cardiol 2012; 15(2): 217-221. https://dx.doi.org/10.1016/i.amjcard.2012.03.018.

18. Kleczynski P, Dziewierz A, Rakowski T, Rzeszutko L, Sorysz D, Legutko J, Dudek D. Cardioembolic acute myocardial infarction and stroke in a patient with persistent atrial fibrillation. Int J Cardiol 2012; 161(3): 4647. https://dx.doi.org/10.1016/j.ijcard.2012.04.018.

19. Guo Y, Lip GY, Apostolakis S. Inflammation in atrial fibrillation. J Am Coll Cardiol 2012; 4(22): 2263-2270. https://dx.doi.org/10.1016/j.jacc.2012.04.063. 
20. Sandoval Y, Smith SW, Thordsen SE, Apple FS. Supply/demand type 2 myocardial infarction: should we be paying more attention. J Am Coll Cardiol 2014; 63: 2079-2087. https://dx.doi.org/10.1016/i.jacc.2014.02.541.

21. Melikulov AKh, Maglakelidze DA. The possible mechanisms and strategies for preventing of atrial fibrillation after open-heart surgery. Annaly Aritmologii 2012; 9(1): 13-19. Russian. https://elibrary.ru/item.asp?id=17888506.

22. Aranki SF, Shaw DP, Adams DH, et al. Predictors of atrial fibrillation after coronary artery surgery. Current trends and impact on hospital resources. Circulation 1996; 94(3): 390-397. https://dx.doi.org/10.1161/01.CIR.94.3.390.

23. Tsigkas G, Kopsida G, Xanthopoulou I, Roussakis GN, Michaelides AP, Kartalis AN, et al. Diagnostic accuracy of electrocardiographic STsegment depression in patients with rapid atrial fibrillation for the prediction of coronary artery disease. Can J Cardiol 2014; 30(8): 920924. https://dx.doi.org/10.1016/j.cjca.2014.03.023.

24. Wierzbowska-Drabik K, Cygulska K, Cieslik-Guerra U, Uznanska-Loch B, Rechcinski $T$, Trzos E, et al. Circumferential strain of carotid arteries does not differ between patients with advanced coronary artery disease and group without coronary stenoses. Adv Med Sci 2016; 61(2): 203-206. https://dx.doi.org/10.1016/j.advms.2015.12.010.

25. Pradhan R, Chaudhary A, Donato AA. Predictive accuracy of ST depression during rapid atrial fibrillation on the presence of obstructive coronary artery disease. Am J Emerg Med 2012; 30(7): 1042-1047. https://dx.doi.org/10.1016/j.ajem.2011.06.027.

26. Abidov A, Hachamovitch R, Rozanski A, Hayes SW, Santos MM, Sciammarella MG, et al. Prognostic implications of atrial fibrillation in patients undergoing myocardial perfusion single-photon emission computed tomography. J Am Coll Cardiol 2004; 44(5): 1062-1070. https://dx.doi.org/10.1016/i.jacc.2004.05.076.

27. Elabbassi W, Chowdhury MA, Brano Liska, Hatala R. Clinical profile and angiographic findings among patients with atrial fibrillation presenting for selective coronary angiography. Health (N Y) 2014; 6(1): 44-50. https://dx.doi.org/10.4236/health.2014.61007.

28. Lokshyn S, Mewis C, Kuhlkamp V. Atrial fibrillation in coronary artery disease. Int J Cardiol 2000; 15(2): 133-136. https://dx.doi.org/10.1016/S0167-5273(99)00180-1.

29. Motloch LJ, Reda S, Larbig R, Wolff A, Motloch KA, Wernly B, et al. Characteristics of coronary artery disease among patients with atrial fibrillation compared to patients with sinus rhythm. Hellenic J Cardiol 2017; 58(3): 204-212. https://dx.doi.org/10.1016/j.hjc.2017.03.001.

30. Rubboli A, Faxon DP, Juhani Airaksinen KE, Schlitt A, Marín F, Bhatt DL, et al. The optimal management of patients on oral anticoagulation undergoing coronary artery stenting. The 10th Anniversary Overview. Thromb Haemost 2014; 112(6): 1080-1087. https://dx.doi.org/10.1160/TH14-08-0681.

31. Lip GY, Windecker S, Huber K, Kirchhof P, Marin F, Ten Berg JM, et al. Management of antithrombotic therapy in atrial fibrillation patients presenting with acute coronary syndrome and/or undergoing percutaneous coronary or valve interventions: a joint consensus document of the European Society of Cardiology Working Group on Thrombosis, European Heart Rhythm Association (EHRA), European Association of Percutaneous Cardiovascular Interventions (EAPCI) and European Association of Acute Cardiac Care (ACCA) endorsed by the Heart Rhythm Society (HRS) and Asia-Pacific Heart Rhythm Society (APHRS). Eur Heart J 2014; 35(45): 3155-3179. https://dx.doi.org/10.1093/eurheartj/ehu298.

32. Belkorey OS, Khasanov HR, D'yakova EN. Impact of atrial fibrillation on development of in-hospital complications of myocardial infarction. $\begin{array}{lll}\text { Medical Alphabet 2016; 2(28): 25-27. Russian. } & \end{array}$ https://elibrary.ru/item.asp?id=28300711.

33. Andrade JG, Deyell MW, Khoo C, Lee M, Humphries K, Cairns JA. Risk of bleeding on triple antithrombotic therapy after percutaneous coronary intervention/stenting: a systematic review and meta-analysis. Can J Cardiol 2013; 29(2): 204-212. https://dx.doi.org/10.1016/j.cjca.2012.06.012.
34. Pruszczyk P, Tomaszuk-Kazberuk A, Słowik A, Drwila R, Rydzewska G, Filipiak KJ, et al. Management of bleeding or urgent interventions in patients treated with direct oral anticoagulants (DOACs) management proposals in Poland. Pol Arch Intern Med 2017; 127(5): 343-351. https://dx.doi.org/10.20452/pamw.3995.

35. Gibson CM, Mehran R, Bode C, Halperin J, Verheugt FW, Wildgoose P, et al. Prevention of bleeding in patients with atrial fibrillation undergoing PCl. N Engl J Med 2016; 22(25): 2423-2434. https://dx.doi.org/10.1056/NEJMoa1611594.

36. Gibson CM, Pinto DS, Chi G, Arbetter D, Yee M, Mehran R, et al. Recurrent hospitalization among patients with atrial fibrillation undergoing intracoronary stenting treated with 2 treatment strategies of rivaroxaban or a dose-adjusted oral vitamin $\mathrm{K}$ antagonist treatment strategy. Circulation 2017; 135: 323-333. https://dx.doi.org/10.1161/CIRCULATIONAHA.116.025783.

37. Dewilde WJ, Oirbans T, Verheugt FW, Kelder JC, De Smet BJ, Herrman $J P$, et al. Use of clopidogrel with or without aspirin in patients taking oral anticoagulant therapy and undergoing percutaneous coronary intervention: an open-label, randomised, controlled trial. Lancet 2013; 381(9872): 1107-1115. $\quad$ https://dx.doi.org/10.1016/S01406736(12)62177-1.

38. Fiedler KA, Maeng M, Mehilli J, Schulz-Schüpke S, Byrne RA, Sibbing D, et al. Duration of triple therapy in patients requiring oral anticoagulation after drug-eluting stent implantation: the ISAR-TRIPLE Trial. J Am Coll Cardiol 2015; 65(16): 1619-1629. https://dx.doi.org/10.1016/j.jacc.2015.02.050.

39. Lopatowska P, Tomaszuk-Kazberuk A, Mlodawska E, BachorzewskaGajewska H, Malyszko J, Dobrzycki S, et al. Do CHA2 DS2 VASc and HAS-BLED scores influence 'real-world' anticoagulation management in atrial fibrillation? 1556 patient registry from the reference cardiology centre, Pharmacoepidemiol. Drug Saf 2015; 24(12): 1297303. https://dx.doi.org/10.1002/pds.3878.

40. Heidbuchel $H$, Verhamme $P$, Alings $M$, Antz M, Diener HC, Hacke W, et al. Updated European Heart Rhythm Association Practical Guide on the use of non-vitamin $\mathrm{K}$ antagonist anticoagulants in patients with nonvalvular atrial fibrillation. Europace 2015; 17(10): 1467-1507. https://dx.doi.org/10.1093/europace/euv309.

\section{Authors:}

Olga L. Bockeria - MD, DSc, Professor, Corresponding Member of the Russian Academy of Sciences, Principal Researcher, Department of Surgical Treatment for Interactive Pathology, Bakoulev Scientific Center for Cardiovascular Surgery, Moscow, Russia. http://orcid.org/0000-0002-77118520.

Tatyana G. Le - MD, Department of Surgical Treatment for Interactive Pathology, Bakoulev Scientific Center for Cardiovascular Surgery, Moscow, Russia. 